\title{
Puppetry of the Pixel: Producing Live Theatre in Virtual Spaces
}

\author{
J. R. Parker \\ Digital Media Laboratory \\ Department of Art \\ University of Calgary \\ 14032206784 \\ jparker@ucalgary.ca
}

\author{
Clem Martini \\ Department Of Drama \\ University of Calgary \\ CHD 209 \\ martini@ucalgary.ca
}

\begin{abstract}
The Digital Media Laboratory has spent a significant portion of 2009 exploring the creation of theatrical performances in the online world Second Life. This has taught us practical methods for direction and stagecraft in virtual spaces, and has shown the advantages and limitations of such performances.

A virtual space has the advantages of being easily accessible, flexible, and tolerant of mistakes - an scenery can be taken down and rebuilt in minutes. Set design can be done in three dimensions, and the first draft is often a prototype of what will actually be used. Some scripts that would otherwise be impossible to mount in a conventional theatre are relatively easily produced in Second Life.
\end{abstract}

This kind of performance in a virtual arena raises provocative questions regarding future directions in theatre design, delivery, education and the very nature of performance. Is Second Life the likely arena for a new wave of alternative theatre?

\section{INTRODUCTION}

Last year, while live artistic performances showed an overall decline in attendance, 47 million Americans chose to view theatrical, musical, or dance performances at least weekly using the Internet [10]. Americans are using New Media and the Web and the more and more, and are attending live performances less and less. The only categories where attendance has increased since 2002 are for musical plays and some forms of dance. In all other instances plays, classical and jazz concerts, ballet, and opera - attendance has declined, in some cases by $12 \%$ [9]. There is a need to look technically and creatively at ways to offer new online forms for the next decade.

There is a vast array of online media from which arts audiences can choose, and a selection of delivery mechanisms. The most common include Internet video sites and streams, mp3 and mp4 downloads, and live performance venues like Ustream [1] and various live webcast sites. A form of performance that has been slower to develop is that of live theater. It may be that the usual audiences are more dedicated to the real ambiance of a theater, or it may be that the use of video as a medium for theatre seems too much like television. There is, however, another option - virtual theatre [4.20,21].

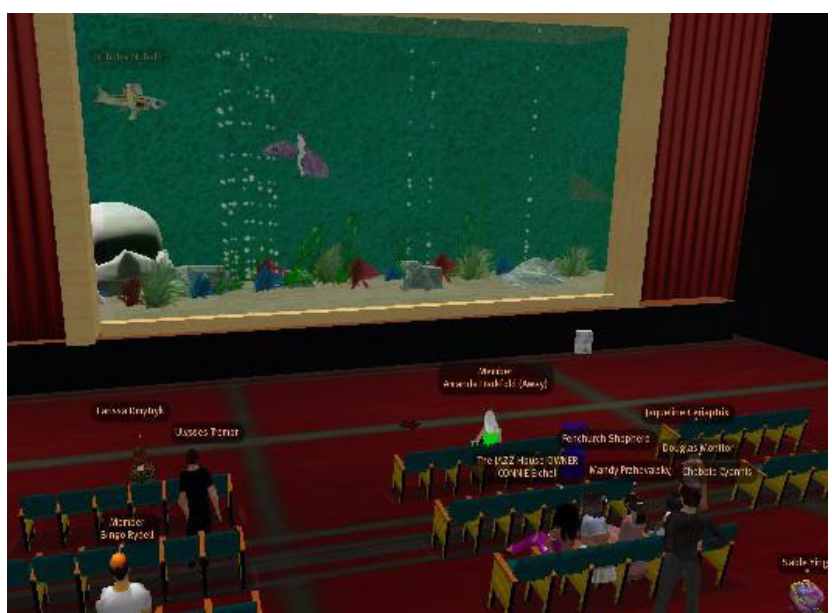

Figure 1: A screen shot from a live performance of Guppies [12] showing the stage and audience. The aquarium set is impossible to build in reality, the actors represent fish and they swim in a tank while delivering their lines.

The definition of virtual theatre to be applied in this article is a theatrical performance in a virtual space [3,11]. The audience does not watch a video, neither are the actors filmed or otherwise prerecorded; all navigate in a threedimensional computer generated space within which the performance is conducted. The performance is live in that it is conducted in real time (with provisos) by real performers (with some exceptions).

The UNESCO educational group's definition of virtual reality is 1 :

an immersive and interactive simulation of either reality-based or imaginary images and scenes.

This could be a practical definition of a theatrical performance in general. The role of the director of a play is to engage the audience (immersion) in an experience that is a narrative based on reality or fiction presented in real time on a stage by people pretending to be participants in the experience (simulation) [5].

This work draws from the experiences gleaned from a series of productions carried out in 2009 and will discuss

1. www.unesco.org/education/educprog/lwf/doc/portfolio/ definitions.htm 
the preparation needed for a performance in the context of a virtual online stage. The use of Second Life [2] will be discussed, but other virtual worlds would have very similar characteristics.

\section{TECHNOLOGY OF VIRTUAL WORLDS, IN BRIEF}

A virtual world is really an artifact of 3D graphics. Polygons and solid objects are used to build graphical constructions within a simulated 3D volume, and these are rendered from a particular viewpoint. The viewpoint can be moved by a human viewer, usually using their mouse and keyboard, and this changes the way the scene appears from that viewpoint. A representation of the viewer called an avatar is normally drawn at the viewpoint; it is natural for a person to assume that a visual perspective is a representation of the world from their point in space, and so the user controls the avatar, and the avatar 'sees' the space by rendering the scene from that point.

A typical video game is a good example of this kind of virtual space, but would be mostly unusable for live performances, being isolated from anyone but the player. An online video game, on the other hand, has a real-time link to the Internet, and could provide a stage for some kinds of performance. Such games consist of a client-server system, with the client acting as a user-local display system and the server holding a description of the larger virtual space and its contents and interactions.

The basic scheme is as follows: a user presses a key, moving their avatar and changing their visual perspective. The new coordinates and viewpoint are sent to the server, which determines whether anything new can be seen, whether any collisions have occurred, and whether any events of any kind have taken place within the viewing volume. Such changes are transmitted to the client, not as images but as objects and positions within the volume; the client then renders the scene and displays it.

This scheme can be used for theater because avatars of other users (players) are objects that can move about and be rendered within the volume. Avatars can interact with each other, and deliver audio, motion, and gestures. The virtual world Second Life [2,14] works in this manner, and has been the main venue for virtual theater so far.. Of the nongame sites it is clearly the most popular (16 million user accounts).

\section{STAGECRAFT IN SECOND LIFE}

Stagecraft refers to the technical aspects of a theatrical production. It includes basically all of the details that define the visual and auditory appearance of the show, including set design and construction, costumes, props, lighting, and makeup. It is a very practical field, and is all about giving form to the director's and writer's artistic vision.

A production begins with a script; the production manager must scan each word to identify all assets and cues. Assets include scenery and set items, props, and costumes. Designers work with these items to create a consistent visual presentation. Cues are indicators to the technical staff that an action is to take place. For example, when the script indicates that an actor switches a light on, this becomes a cue to the lighting technician to turn a new light on. Actors almost never really control anything on the stage; everything is done by technical people behind the scenes. Cues tend to concern either lights or sounds, but can include mechanical or physical cues (E.g. things falling or being set on fire).

In virtual theatre, because objects (props, sets) are in some sense unreal, and because the actors are avatars controlled through computer interfaces, there are two more kinds of cues that are crucial to identify: gestures and object interactions.

\section{Gestures}

The term gesture is used to describe any motion by an actor, whether involving motion, or posing arms or legs. The arrow keys are used to control the basic direction of motion of an avatar. This allows for a basic walking motion, but not jumping or skipping, arm motions, or hand gestures. These latter can be accomplished by creating an animation: "a set of instructions that cause an avatar to engage in a sequence of motions [6]."

A gesture is implemented as a sequence of joint angle changes of the avatar, carefully timed in three dimensions. This is classic motion capture data, and in fact is most commonly stored as Biovision Hierarchy Files (BVH) [14] as created a modeling program (E.G. Maya). Our group uses a free tool called Avimator [13], and also has access to a Gypsy 6 motion capture system [11] that can take motions from actors in real time and create BVH files. However acquired, the recorded motions are uploaded to the server and can then be played on cue; that is, when a specified key is pressed, the avatar joint angles will be varied as a function of time so as to make the avatar move through the gesture.

\section{Object Interactions}

Having an actor pick up a coffee cup and drink from it involves a gesture, but also an interaction with a prop - the cup. In virtual spaces this can be the most difficult aspect of a performance. There is no standard or natural interaction with the props. They seem to be physical objects, but are in

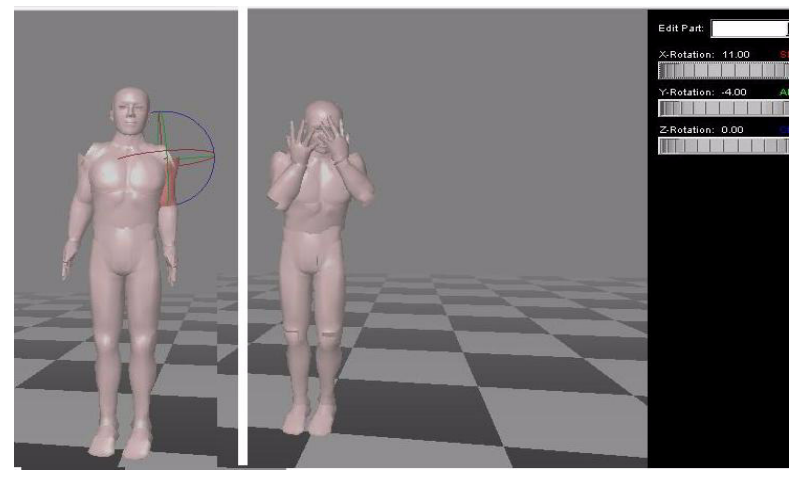

Figure 2: $\quad$ Using Avimator to create a 'peek-a-boo' gesture. Each joint in the body can be moved through its angular range in each dimension using the dials at the right. 

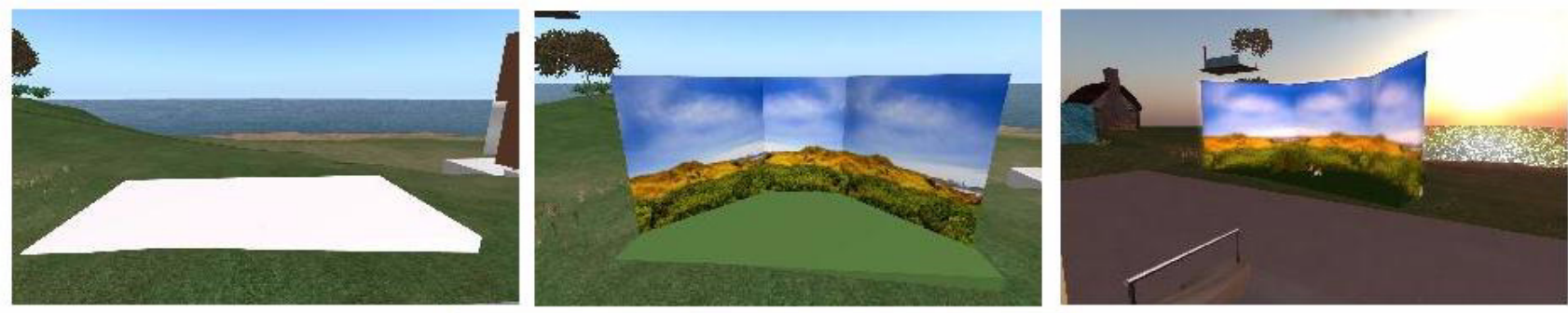

Figure 3: Set construction

(Top) Steps in the construction of an 'outdoor' scene using billboards, textures, animations (the fire) and built objects. (Right) How the set looks, including an actor.

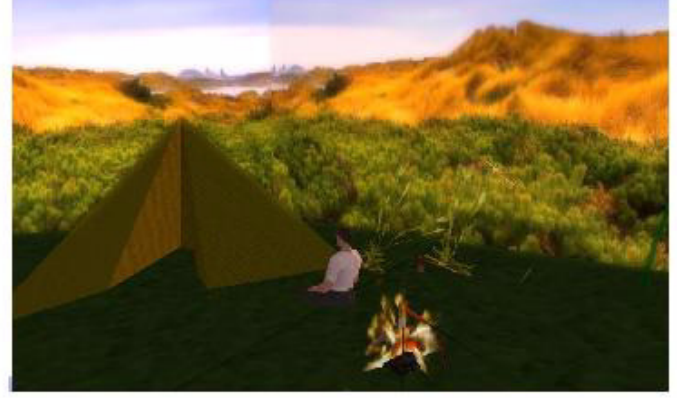

fact merely constructs of polygons, shading, and lighting. In order to interact with them, the interaction must be located (from the script), carefully defined as a set of attachments to other objects and/or changes in position and orientation, and then implemented.

Implementing an interaction is done using software that has to be written specifically for each one. In confusing terminology, the program that codes for the interaction is usually called a script, and is written in a scripting language. In Second Life the Linden Scripting Language (LSL) allows a programmer to, for example, attach a cup to an avatar's hand, execute a short animation for the drinking gesture, and then detach the cup and attach it to a table or saucer. Every interaction must be implemented at this level of detail, and no accidental interactions are even possible.

\section{Set Design and Construction}

In Second Life, all constructed objects are built in three dimensions from the outset. For contrast, consider that a great deal of set design is done using tools like Vector works, which is really a fundamentally 2D CAD system. Such systems require that the designer work in $2 \mathrm{D}$ with the final 3D result in mind. The third dimension is accomplished through extrusion.

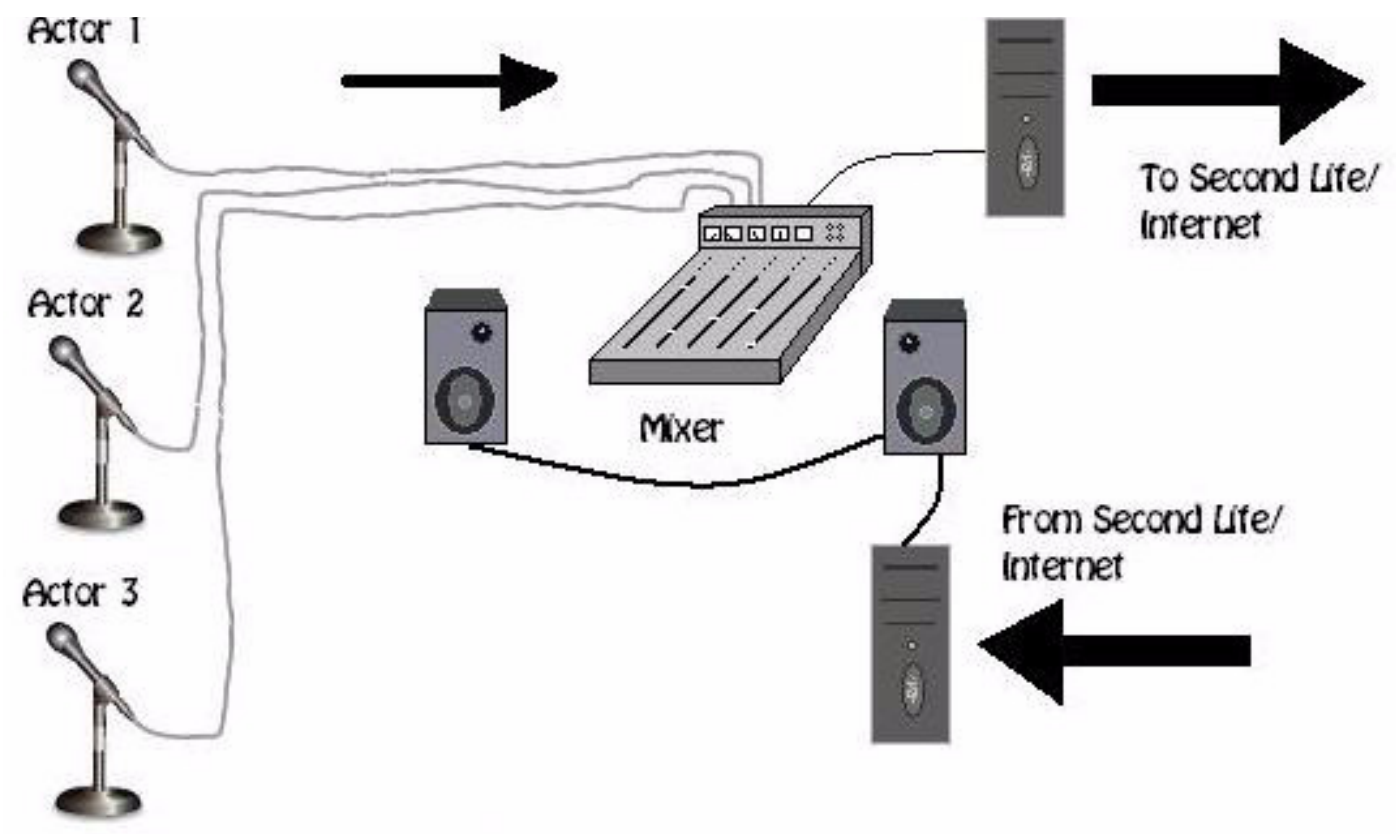

Figure 4: An audio set-up for a live performance. Actors sit before their own microphones, which are tied to a mixer. The mixer feeds sound to a computer, through the second life client, and the to virtual space. A second computer receives the audio from second life and allows the sound technician to monitor it. 

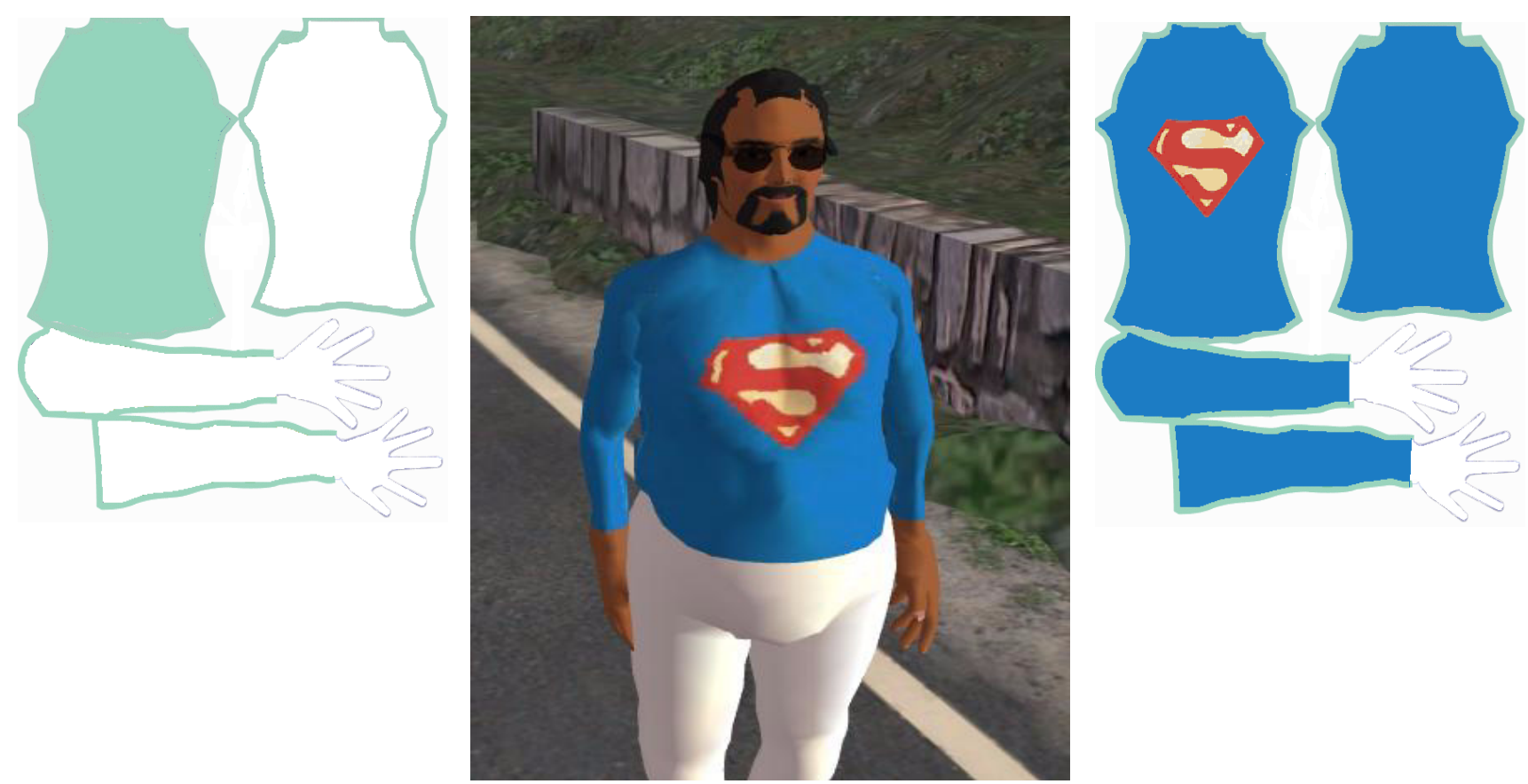

Figure 5: $\quad$ Costume design and construction. (Left) A template (JPEG image) for a male shirt. (Right) A design overlaid on the template. (Center) The design is downloaded to second life and is worn as a shirt. Templates are available for pants, skirts, etc.

Second Life and similar tools requuire the designer to start with a 3D object. In this solid modeling scheme the primitives are not polygons, but are cubes, spheres, and prisms. These 'prims' can be hollowed out, twisted, sheared, cut, and combined in dozens of ways. The surface of the objects can be given textures (uploaded images). Objects can be colored, made transparent, and even glow.

For virtual theatre, the value of this capacity can't be over stated. The result is a working model that can be seen from any perspective and can also be used immediately in blocking and rehearsals. A complete set can be constructed in a matter of hours, used, and rebuilt if necessary to accommodate perceived problems.

\section{Costume}

Costume design often starts with pencil sketches or renderings using simple drawing software. The specific process depends on the designer, of course. In Second Life, a sketch can be made on a simple 2D template that can, in minutes, be uploaded and incarnated within the virtual space as an item of clothing on the body of an avatar. Iterations can be accomplished in minutes that used to require days; the costume can be viewed in 3D on a moving body within minute of conception. Figure 5 shows this process.

\section{Sound}

Sound was the most difficult aspect of the production to get right, and is the most important. The first plays in Second Life used a text chat facility supplemented by a prerecorded sound track, but to mount a production properly there really needs to be a way to allow the actors to deliver their lines. This occurred when voice chat was added to most online worlds in 2006-2007.

There are many configurations of sound equipment that can work for effective virtual theatre, and an even greater number that will not. For example, voice chat has a delay due to latency of between $1 / 2$ to 1 second. It is therefore not possible to allow the actors to hear their voices as transmitted back from the virtual stage. The delay confounds the delivery of their lines. Thus, a direct connection of the actor to Second Life through a single computer is not the best choice.

Figure 4 shows an audio configuration that has been effective in productions our group has mounted. Each actor has a microphone connected to an audio mixer, and each has their own computer for moving their avatar, but with all sound turned off. The mixer feeds sound into a computer that is connected to Second Life, and that in turn sends the sound down one voice chat channel to the stage. A second computer, with a second avatar within the same virtual space, is used to hear what is happening. The sound technician controls the sound as heard using the second computer. The short delay is acceptable for setting levels, and gives better volume levels than other options.

We connect the mixer through an attenuator to the microphone input of the computer. It simplifies the audio settings, which vary by operating system and sound card. This means the same computer can be used to send sound effects. We have constructed a simple sound cue player in Java that pre-loads sound files, and plays then with a single mouse click. 


\section{REHEARSALS}

After the first readings of the script during which cues are noted, the actors rehearse by reading the script aloud through their mics. Initially no avatar motion is performed. The first readings allow the actors to get a feel for the play and think about delivery and actions. Actors and technicians work together on the gestures, and in a subsequent run though add motion and gestures. An initial set can be built for the first rehearsal and is adjusted according to the needs of the director and actors, sometimes on a daily basis.

One of the advantages of virtual theatre is the degree to which there is mutual feedback. Not only do the actors adjust to the sets, sounds, and stage directions, but the reverse is easy to accomplish; sets can be changed on very short notice to accommodate a new idea or to solve a problem. Recordings of the rehearsals are easy to make, and can be used for immediate feedback.

\section{PERFORMANCE}

Online performances can be reached by nearly anyone on Earth without expense or travel time. Ours took place in the New Media Consortium Art Center, and was attended by curious fans from all over the world. It is set up as a standard proscenium stage with audience seating,, but there's no need for this setup. As virtual theatre develops new kinds of presentation will develop that take better advantage of the space.

We selected plays that take advantage of virtual spaces. Our first, Guppies [8], is an exchange between fish. We built a large aquarium as the set, in which our fish characters swam about. Other productions involved a genie, living and speaking chocolate treats, and a giant black widow spider. Such things are difficult to present effectively on a live stage.

\section{CONCLUSIONS}

Virtual theatre techniques have the potential to change the way live in-person theatre is conducted. Virtual theatre is also a new extension of an old art form, and is an attractive entertainment form with virtual spaces, which is a place many people come both to play and to work. It shows some potential to widen the audience of live theatre, to interest a younger audience, and to simplify the act of attending theatre. The process of mounting the performance can be more democratic than traditional theatre, allowing feedback from many sources, and encouraging a rapid prototyping system of development.

This is still in an initial state, and will profit from higher resolution graphics, better audio, and most of all by better avatar control systems. We are working on the use of motion capture so that actor movements can be translated into avatar motions in real time. Facial animation is also a crucial technology for future success - the facial animation for the film Avatar by Image Metrics [12] is an example of what can be done, and of how quickly such technologies can change.

\section{REFERENCES}

1. Broida, Rick (2007) Ustream At A Glance, PC Magazine, August 7, 2007 (http://www.ustream.tv/)

2. Catherine Linden. (2007) Introducing the Second Life Grid, https://blogs.secondlife.com/community/features/ blog/2007/09/05/introducing-the-second-life-grid, Sep 5,2007

3. Dinkla, S. (1996) From Participation to Interaction: Toward the Origins of Interactive Art. Clicking In: Hot Links to a Digital Culture, ed. Hershman Leeson, L, 279 - 290.

4. Flanagan Mary . (2004) Developing Virtual Performance Spaces, American Puppetry. Ed. Phyllis T. Dircks. New York: Theatre Library Association.

5. Geigel, Joe and Schweppe, Marla. (2004) Theatrical storytelling in a virtual space, Proceedings of the 1st ACM workshop on Story representation, mechanism and context, Pages: 39 - 46

6. Linden Research, (2007) Animation, http://wiki.secondlife.com/wiki/Animation

7. McKenzie, J. (1994, Winter) Virtual Reality: Performance, Immersion, and the Thaw, TDR Cambridge, Mass. 38 (4), 83

8. Martini, Clem (2001) Guppies. Festival of Ten, SUNY Brockport.

9. National Endowment for the Arts. (2009) 2008 Survey of Public Participation in the Arts, http:// www.nea.gov/research/2008-SPPA.pdf

10. Trescott, Jacqueline. (2009) Web audience grows for arts groups, Washington Post, December 10, 2009.

11. Vlasic, Daniel et al (2007). Practical motion capture in everyday surroundings, ACM Transactions on Graphics (TOG) Volume 26, Issue 3 (July 2007)

12. Waxman, Sharon (2006) Cyberface: New Technology That Captures the Soul, New York Times, October 15, 2006.

13. Webb, Rubin. (2007). A Beginners Guide to Avimator, http://www.avimator.com/downloads/ Avimator_Beginners_Guide.pdf

14. Weber, Aimee; Rufer-Bach, Kimberly and Platel, Richard (2008). Creating Your World - The Official Guide to Advanced Content Creation for Second Life, Wiley Publishing.

15. Yildiz, Pelin. (2007) The Multimedia Interactive Theatre by Virtual Means Regarding Computational Intelligence in Space Design as HCI and Samples from Turkey, Proceedings Of World Academy Of Science, Engineering And Technology Volume 25 November

16.Zellner, Dan (2008) Toward A Virtual Theatre, International Journal of Computational Science, 2008, Vol. 2, No. 1, 21-28. 